Time for another change

\section{Washington}

US and world agriculture is ready for its third major change this century according to a report released by the US National Research Council, the research arm of the National Academy of Sciences. After the mechanization of agriculture, which began early in the century, and the introduction of chemical fertilizers, pesticides and high-yielding crop varieties which produced the 'green revolution' of the 1960 s, will come 'alternative' farming that uses skilful management to take advantage of the biological relationships that occur naturally on the farm.

Alternative Agriculture is a 450-page report produced by a committee of 17 researchers from 11 US universities and is based on detailed studies of 14 US farms where alternative farming practices were being tried out. Although the title of the report suggests an association with the 'alternative society' of the $1960 \mathrm{~s}$, the report makes plain that "the hallmark of an alternative farming approach is not the conventional practices it rejects but the innovative practices it includes".

The overall objective is said to be to enhance and sustain useful biological relations rather than to reduce and simplify them through conventional monocultures and blanket application of pesticides and herbicides. As examples of the alternative approach the report notes:

-Genetic improvement of crops to resist pests diseases and drought, and to use nutrients more effectively.

-The planting of a diversity of crops rather than a single one. Crop rotation can reduce problems from weeds, disease and pests and cut fertilzer use and soil erosion. -Reliance on the prevention of disease in animals rather than frequent use of antibiotics.

-Integrated pest control methods.

Integrated pest control uses ecological principles to capitalize on natural pest mortality, predator-prey relations, genetic resistance and the effect of the precise

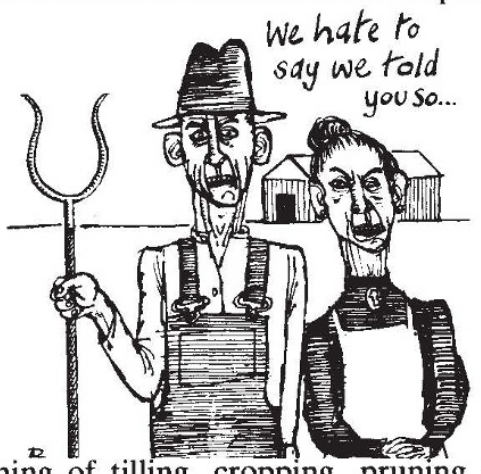

timing of tilling, cropping, pruning and pesticide application. Typically, integrated pest management requires fields to be 'scouted' to determine pest and disease levels before deciding what form of minimal intervention is best. The overall effect can be to reduce pesticide use and to make the farm more productive.

John Pesek, chairman of the NRC committee and head of the department of agronomy at Iowa State University, argues that alternative agriculture is economically successful chiefly because it reduces the cost of "off-farm inputs" such as fertilizers and pesticides, while maintaining productivity.

"Successful alternative farmers do what all good managers do. They apply management skills and information to reduce costs and improve efficiency while maintaining yield levels", he says.

The report's good news is that alterna-

\title{
EC announces bovine hormone moratorium
}

Munich

IN the middle of this month, European Agriculture Commissioner Ray McSharry made the long-expected announcement of a 15-month moratorium on the use of the genetically engineered hormone bovine somatotropin (BST). The moratorium is to allow for further study of the product. McSharry had been expected to propose a ban in August, but the Commission of the European Communities (EC) shied away in the face of pressure from the United States (see Nature 340,$415 ; 1989)$.

The moratorium (which the EC prefers to call a "period of evaluation") must still be approved by the Council of Ministers, which will meet soon to discuss the matter. The European Parliament has also been asked to comment. The commission will issue a report based on the studies by
October, 1990. A decision on licensing is expected to follow.

Clayton Yuetter, the US Secretary of Agriculture, has backed away from the threatening position he took in July when the moratorium was first discussed. He said he accepted the EC proposal as long as it was linked to scientific studies. But "a delay of 20 years" would not meet that criterion, he said.

US and EC officials are struggling to avoid a trade war over BST, which is expected to set a precedent for the licensing of other biotechnology products in Europe. Yuetter said that if the EC wants to reject BST on grounds other than efficacy, safety and quality - for example on economic grounds - then it should say so in the GATT international trade negotiations. Steven Dickman tive methods work and through reduced pesticide use and better soil management, could help to ameliorate conventional agriculture's problems - 3,000 million tons of topsoil erode from US farms each year, and pesticides and fertilizers in agricultural run-off, when added to the silt, are major causes of water pollution. But the bad news is that federal farming programmes make it very difficult to deviate from conventional farming practices. Seventy per cent of US cropland is covered by commodity programmes designed to shield farmers from fluctuating prices. One effect is that any practice that reduces acreage planted to a programme crop reduces the acreage eligible for subsidies for the next five years. Thus, if a farmer switches from corn to alfalfa for one year to increase nitrogen in the soil, he will incur an extended loss of subsidies.

Commodity programmes also base future payments on past production. While this system has helped to push up US agricultural production, it has also encouraged farmers to cultivate marginally productive land and to use levels of fertilizer and pesticide that would make little sense without incentives. The result, the report says, is that many farmers simply aim to "maximize present and future program benefits".

Other programmes encourage massive use of pesticides by setting cosmetic standards for fruit that have little bearing on nutritional quality. Tolerance of minor surface blemishes would permit major reductions in pesticide use.

The committee recommends that federal commodity programmes, which cost $\$ 14,000$ million a year, be restructured "to help farmers realize the full benefits of the productivity gains possible through many alternative practices". At a minimum, the programmes should be changed to encourage crop rotation.

The US Department of Agriculture (USDA) has generally welcomed the report and accepted that change is needed. But the challenge will be to provide farmers with the much higher level of training and information they need to adopt new practices. That help is not available from traditional sources such as USDA, extension agents or agricultural supply dealers. The report calls for a new $\$ 40$ million competitive grants programme for alternative agriculture research, along with increased funds for demonstration and implementation of the research results.

Pesek says he cannot predict the precise economic effects of the widespread use of alternative agriculture. But he says the committee is convinced the methods work, and that they would produce an ample food supply while reducing environmental problems. The potential benefits, he says, are "too attractive to continue to lie fallow". Alun Anderson

NATURE · VOL $341 \cdot 28$ SEPTEMBER 1989 